\title{
Hand Schuller Christian disease
}

Sir,

A 43-year-old lady presented with progressively increasing multiple swellings over the scalp for two years and increased frequency of micturition and increased water intake for 6 months. There was no evidence of other systemic involvement. Computerized tomography (CT) of the brain showed multiple geographic punched-out lesions with nonsclerotic margins and beveled edges, associated with well-defined nonenhancing hypodense cystic lesions. The pituitary stalk appeared normal. She underwent excision biopsy of the right frontal skull lesion which was consistent with histiocytosis $\mathrm{X}$.

Hand Schuller Christian disease (HSC) is one of the three components included in histiocytosis $\mathrm{X}$, the other two being eosinophilic granuloma and Letterer-Siwe disease. This disease is primarily seen in infants and children and is rarely seen in adults. The classical triad of HSC disease - exophthalmos, diabetes insipidus, and calvarial lytic lesions - is seen only in one-third of patients. ${ }^{[1]} \mathrm{CT}$ scan is particularly helpful in detecting and defining the bony lesions and the soft tissue involvement. Both the outer and inner tables of the skull are involved with beveled edges and soft tissue masses [Figure 1]. ${ }^{[2]}$ Coalescence of lytic lesions gives a morphological appearance which is termed as "Geographic Skull" [Figure 2]. ${ }^{[3]}$ The bones involved are skull, ribs, pelvis, scapula, and mandible. Vertebrae and the appendages are less frequently involved. Optic atrophy, otitis media, and extrusion of teeth may occur as a result of adjacent bony involvement. ${ }^{[4]}$ Systemic involvement of this disease includes hepatosplenomegaly, lymphadenopathy, dermatological, gastrointestinal tract, renal and pulmonary involvement. Central nervous system involvement includes convulsions, increased intracranial pressure, focal neurological deficits, mental retardation, hearing disturbance, and tremors. Involvement of the pituitary and hypothalamus may result in delay in sexual maturity and bone development, which is often seen in the pediatric age group. ${ }^{[5]}$ The factors indicating the prognosis of this disease include the patient's age at presentation, extent of the systemic involvement, and response to treatment..$^{[1]}$

Goutham Cugati, Manish Singh, Anil Pande, Ravi Ramamurthi, Mathabushi C. Vasudevan

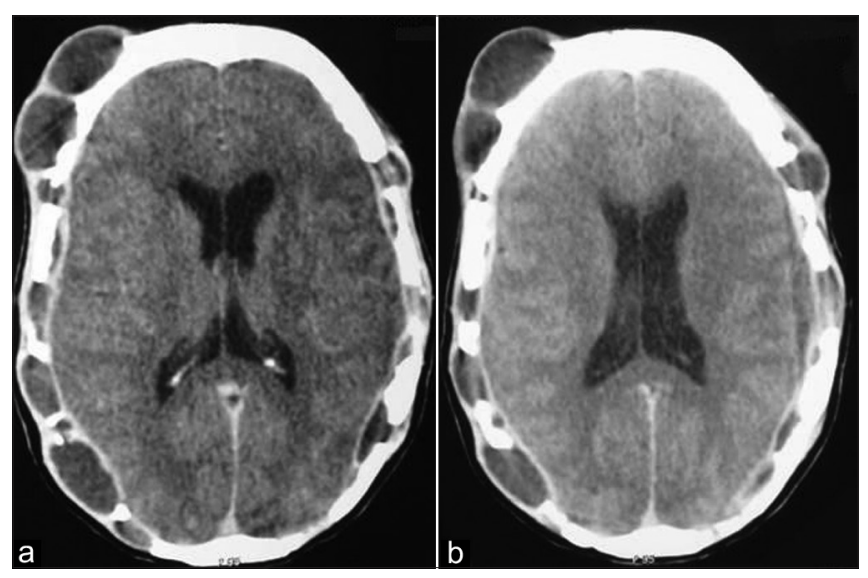

Figure 1 ( $a$ and $\mathbf{b}$ ): CT scan of the brain axial views showing multiple lytic lesions of the cranium involving both inner and outer tables, with underlying normal brain parenchyma. Soft tissue masses seen overlying the pathological areas of the cranium

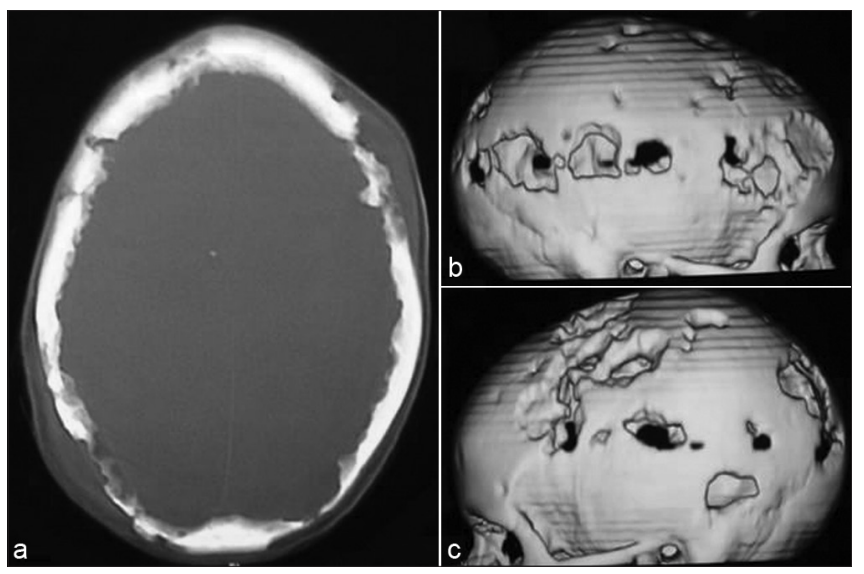

Figure 2: (a) CT scan of the cranial bone views showing multiple lytic lesions with beveled edges. (b-c) CT reconstruction of the bone showing the typical "Geographic Skull" appearance

Dr. Achanta Lakshmipathi Neurosurgical Centre, Post Graduate Institute of Neurological Surgery, VHS Hospital, Chennai, Tamil Nadu, India

\section{REFERENCES}

1. Filho C, Olimar J, Santos M, Neto A, Moacyr J. Histiocytosis $X$ (síndrome de Hand-Schuller-Christian): Relato de caso. Radiol Bras 2002;35:109-12.

2. Meyer JS, Harty MP, Mabboubi S, Heyman S, Zimmerman RA, Womei RB, et al. Langerhans cell histiocytosis: Presentation and evolution of radiologic findings with clinical correlation. Radiographics 1995;15:1135-46. 
3. Shah AK, Solanki RN, Mahajan A. Hand Schuller Christian disease causing diabetes insipidus. Indian J Radiol Imaging 2003;13:297-300.

4. Lucaya J. Histiocytosis X. Am J Dis Child 1971; 121:289-95.

5. Avery ME, McAfee JC, Guild HG. The course and prognosis of reticuloendotheliosis: A study of 40 cases. Am J Med 1957;22:636-42.

\begin{tabular}{|l|l|}
\hline \multicolumn{3}{|c|}{ Access this article online } \\
\hline Quick Response Code: & Website: \\
\hline & www.ijmpo.org \\
\hline
\end{tabular}

\section{"Quick Response Code" link for full text articles}

The journal issue has a unique new feature for reaching to the journal's website without typing a single letter. Each article on its first page has a "Quick Response Code". Using any mobile or other hand-held device with camera and GPRS/other internet source, one can reach to the full text of that particular article on the journal's website. Start a QR-code reading software (see list of free applications from http://tinyurl.com/ yzlh2tc) and point the camera to the QR-code printed in the journal. It will automatically take you to the HTML full text of that article. One can also use a desktop or laptop with web camera for similar functionality. See http://tinyurl.com/2bw7fn3 or http://tinyurl.com/3ysr3me for the free applications. 